\title{
Synthesis of Silver Nanoparticles Using Albumin as a Reducing Agent
}

\author{
Elpidio Morales-Sánchez ${ }^{1,2,3}$, Jesús Guajardo-Pacheco ${ }^{1,2,3}$, María Noriega-Treviño ${ }^{1,2,4}$, \\ Cristina Quintero-González ${ }^{2,4}$, Martha Compeán-Jasso ${ }^{2}$, Francisco López-Salinas ${ }^{1,2,3}$, \\ Jesús González-Hernández ${ }^{3}$, Facundo Ruiz ${ }^{2}$
}

\begin{abstract}
${ }^{1}$ Departamento Físico Matemáticas de la Universidad Autónoma de San Luis Potosí, Álvaro Obregón, Col. Centro, San Luis Potosí, S.L.P., México; ${ }^{2}$ Facultad de Ciencias de la Universidad Autónoma de San Luis Potosí, Álvaro Obregón, Col. Centro, San Luis Potosí, S.L.P., México; ${ }^{3}$ Centro de Investigación en Materiales Avanzados, S.C. (CIMAV), Miguel de Cervantes 120 Complejo Industrial Chihuahua, México; ${ }^{4}$ Doctorado Institucional de Ingeniería y Ciencia de Materiales de la Universidad Autónoma de San Luis Potosí, Alvaro Obregon, Col. Centro, San Luis Potosí, S.L.P., México.

Email: elpidio@uaslp.mx
\end{abstract}

Received February $15^{\text {th }} 2011$; revised March $1^{\text {st }}, 2011$; accepted April $1^{\text {st }}, 2011$.

\begin{abstract}
The preparation of stable, uniformed silver nanoparticles by the reduction of silver ions using albumin is reported in the present paper. It is a simple process for obtaining silver nanoparticles. The samples have been characterized by $X$-ray diffraction (XRD) and transmission electron microscopy (TEM), which reveal the nature of the nanoparticles. These studies conclude that the particles are mostly spherical in shape and have an average size of $26 \mathrm{~nm}$. The UV-vis spectra show that an absorption band, occurred because of the Surface Plasmon Resonance, existing at $443 \mathrm{~nm}$; the Thermogravimetric Analysis (TGA) shows that only $2 \%$ of the weight is organic matter. The average particle size was measured with a Nanosizer DLS.
\end{abstract}

Keywords: Reducing Agent, Albumin, Silver Nanoparticles

\section{Introduction}

With the aim of developing new ways to produce metallic nanoparticles by using materials that are environmenttally friendly, we propose this novel method of producing metallic nanoparticles like Ag, Pt by using albumin as a reducing agent. Improvement in the quality of both the environment and working conditions offers one of the primary reasons for industries to turn to green products as alternatives to chemicals. In this paper, we have reported the synthesis of silver nanoparticles by reducing silver ions, employing albumin as the reducing agent.

The albumin protein was used as a covalent attachment of metal chelates to protein, with a chelate of indium [1]. The stabilization by Natural biosurfactant was used in the synthesis of silver nanoparticles [2]. The soil contamination with toxic metal has become a major environmental concern in many parts of the world due to rapid industrialization. The use of chelating agents is the remediation of metal contaminated soils. [3].

The attachment of metal-chelating groups as albumin and some proteins have been found in medical applica- tions $[4,8]$.

In recent years nanoparticles of silver have been found to exhibit interesting antibacterial activities [9].

A variety of preparation routes have been reported for the preparation of silver nanoparticles. Silver salt reducetion was the most used $[10,15]$.

In the present paper, we report a simple and "green" chemical synthesis of silver nanoparticles from albumin. The silver NPs were characterized by UV-vis absorption spectrum measurements and transmission electron microscopy (TEM),

\section{Materials and Methods}

\subsection{Reagents}

Albumin, $\mathrm{AgNO}_{3}$, purchased from Sigma-Aldrich, and ammonium hydroxide $(29.9 \%$, Fermont) were used without any further purification. Mili-Q water $(18.2 \Omega)$ was used throughout the experiment.

\subsection{Characterization}

The optical absorption spectra were obtained with an 
Oceanoptics S2000-UV-Vis system; transmission electron microscopy TEM images at $100 \mathrm{kV}$ was carried out using a JEOL-1230. Thermogravimetric Analysis (TGA) was made and the average particle size was measured with a Nanosizer DLS.

\subsection{Synthesis of Silver Nanoparticles}

Silver nanoparticles were prepared in an aqueous solution by reducing $\mathrm{Ag}^{+}$ions with albumin solution. The detailed synthetic procedure of silver nanoparticles is as follows: A albumin solution was prepared dissolving 0.1 grams of albumin in $30 \mathrm{ml}$ of deionizer water. Another $\mathrm{AgNO}_{3}$ solution was prepared dissolving 0.05 grams of $\mathrm{AgNO}_{3}$ in $10 \mathrm{ml}$ of deionizer water. The particles were prepared by mixing the silver ion solution with the albumin solution in a magnetic stir and after 5 minutes, 29.9\% ammonium hydroxide was added in drop form, producing an adjustment of $\mathrm{pH}=11$. It was stirred magnetically for $15 \mathrm{~min}$ utes, it was necessary to let the solution settle for 24 hours, because the reaction speed is slow. After that time, the nanoparticles were formed. The silver nanoparticles were recovered by filtration and afterwards washed a minimum of 3 times with ethylic alcohol.

\section{Results and Discussion}

In order to find the $\mathrm{pH}$ at which the albumin has reducing property, we varied the $\mathrm{pH}$ slowly, adding an ammonium hydroxide dilute solution and measured the reducing potential continuously. Figure 1 shows the results and we can see that albumin acts as a reducer with a $\mathrm{pH}$ greater than 10.4. As a result we raised the $\mathrm{pH}$ of the final mix of the silver solution and the albumin solution to 11 .

Colloidal dispersion of metal exhibits absorption bands or broad regions of absorption in the ultra violet-visible range. These are due to the excitation of plasmon resonance or interband transition and are a characteristic property of the metallic nature of the particle. For example, nanosized Ag particles typically exhibit a surface plasmon peak at around $420 \mathrm{~nm}$. To monitor the stability of the final prepared silver nanoparticles, we measured the absorption spectra of the solution when it was prepared we measured it again, six month later. As shown in Figure 2, the silver nanoparticles obtained initially show an absorption peak about $443 \mathrm{~nm}$ (solid line) and the plasmon absorption band of the same sample measured six months after its preparation (dash line) shows only a small change, at $458 \mathrm{~nm}$. The decrease in the absorption of the sample after six months indicates a small increase of silver nanoparticles.

A representative TEM image is shown in Figure 3. The TEM indicates that the morphology of the silver nanoparticles obtained is spherical and relatively uniform; the size distribution observed is narrow. Most of the par- ticles range in size from 5 to $20 \mathrm{~nm}$. We see that the average diameter of the particles is about $13 \mathrm{~nm}$. We can see that the silver nanoparticles are well separated with no sign of aggregation. The mean superficial area is $44 \mathrm{~m}^{2} / \mathrm{g}$.

Figure 4 shows the size distribution of the silver particles obtained with LSD nanosizer equipment. We can see that the diameter of the silver particles is $26.82 \mathrm{~nm}$ with a band width of $6.43 \mathrm{~nm}$, indicating that the size distribution of the silver nanoparticles is narrow. This result is similar to the TEM image we obtained.

In order to find the number of silver nanoparticles and the amount of organic material, we obtained a TGA of a typical sample we had prepared. The TGA is shown in Figure 5.

Three phases of endothermic change are observed. They are marked with the numbers (1), (2), and (3). Point (1) refers to the water evaporation; the sample has $35 \%$

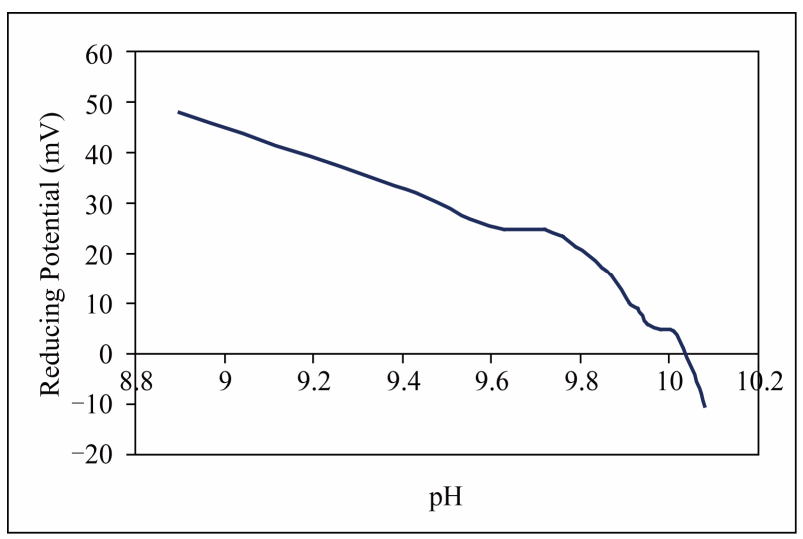

Figure 1. Variation between $\mathrm{pH}$ and reducing potential of albumin solution.

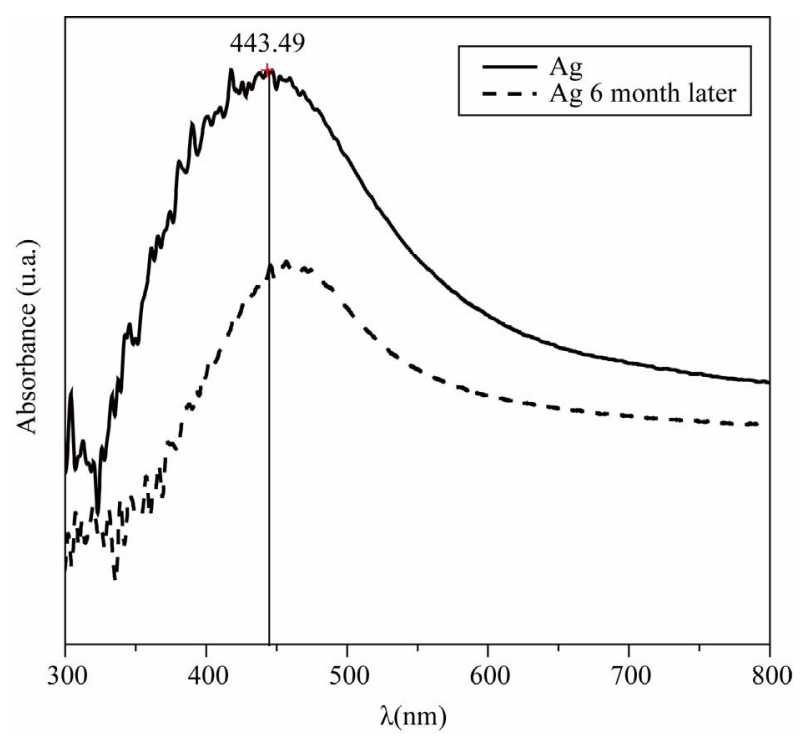

Figure 2. Comparison of UV-vis absorption spectra between samples of $\mathrm{Ag}$ as first prepared (solid line) and six month later (dash line). 


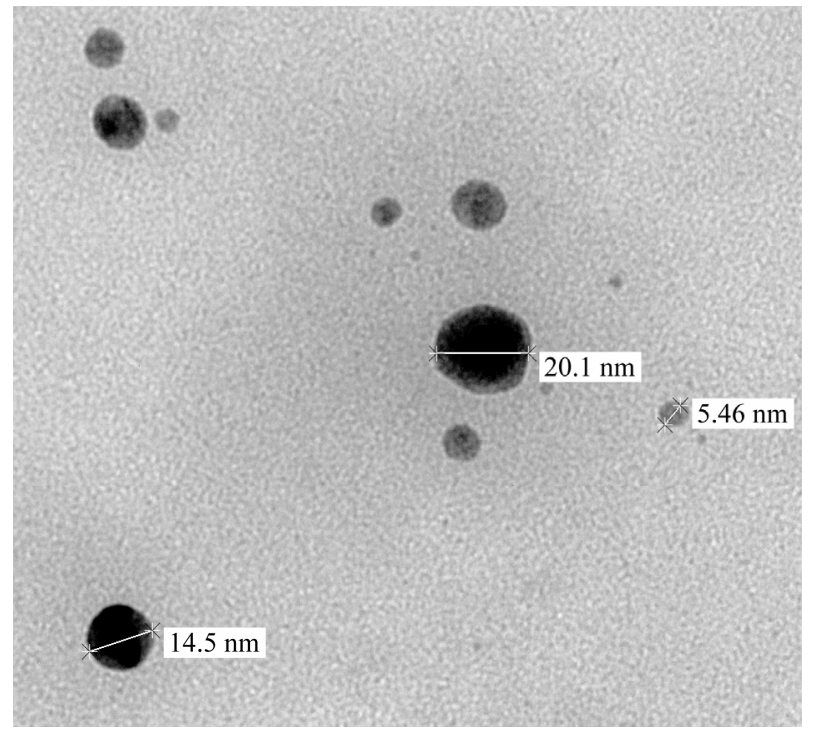

Figure 3. TEM image of a prepared sample silver nanoparticles.

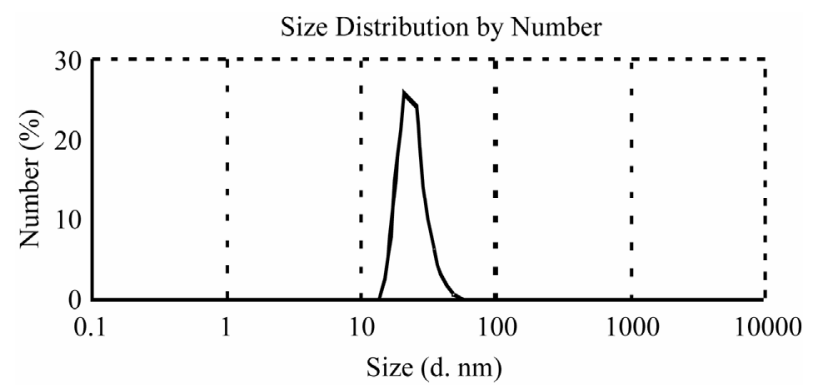

Figure 4. Size distribution of a sample of silver prepared.

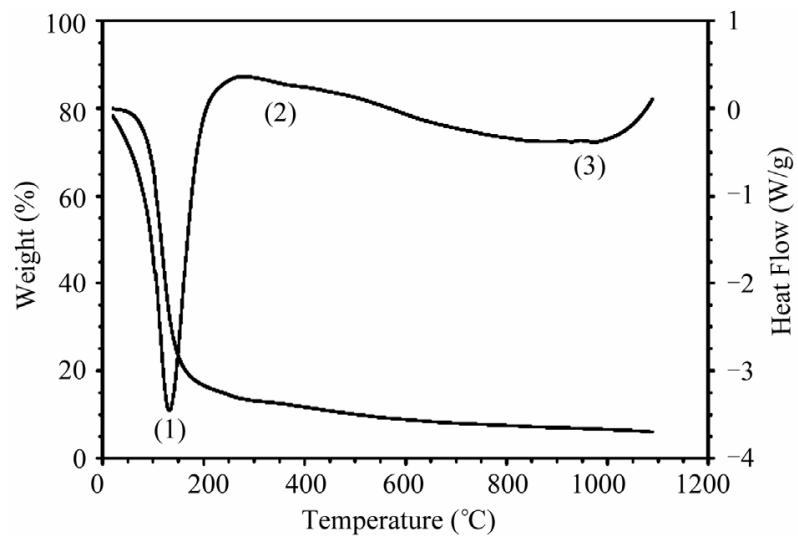

Figure 5. TGA of a sample of silver nanoparticles.

weight of water. Point (2) presents a small shoulder corresponding to organic material decomposition; the quantity of organic material is merely $2 \%$ weight, a very small percentage. It is possible to reduce the organic material further by washing the sample more times. Point (3) represents the fusion of silver particles; the melting point of silver bulk is $961.9^{\circ} \mathrm{C}$, which corresponds to Point (3).

\section{Conclusions}

In conclusion, the bio-reduction of aqueous $\mathrm{Ag}^{+}$ions by the natural "green" albumin has been demonstrated. The silver ion reduction through albumin for the formation of silver nanoparticles of fairly well-defined dimensions. This green chemistry approach toward the synthesis of silver nanoparticles has many advantages such as the ease with which the process can be scaled up, economic viability, etc. Albumin can be used by nanotechnology processing industries. With this method we can obtain a large amount of small silver nanoparticles in a narrow size range. The agglomeration of particles after six months varies only by a small percentage. The morphology of the nanoparticles is spherical. We can say that the stability of the nanoparticles holds well for several months because a high percentage of the particles retain a nanometric size.

\section{REFERENCES}

[1] C. F. Meares, D. A. Goodwin, C. S.-H. Leung, A. Y. Girgis, D. J. Silvesteri, A. D. Nunnf and P. J. Laender, "Covalent Attachment of Metal Chelates to Proteins: The Stability in Vivo and in Vitro of the Conjugate of Albumin with a Chelate of ${ }^{111}$ Indium," Proceedings of the National Academy of Sciences in USA, Vol. 73, No. 11, 1976, pp. 3803-3806.

[2] Y. W. Xie, R. Q. Ye and H. L. Liu, "Synthesis of Silver Nanoparticles in Reverse Micelles Stabilized by Natural Biosurfactant," Colloids and Surfaces A: Physicochemical and Engineering Aspects, Vol. 279, 2006, No. 1-3, pp. 175-178. doi:10.1016/j.colsurfa.2005.12.056

[3] G. A. Brown and H. A. Elliott, "Influence of Electrolytes on EDTA Extraction of PB from Polluted Soil," Water, Air and Soil Pollution, Vol. 62, No. 1-2, 1992, pp 157165. doi:10.1007/BF00478458

[4] S. Tandy, K. Bossart, R. Mueller, J. Ritschel, L. Hauser, R. Schulin and B. Nowack, "Extraction of Heavy Metals from Soils Using Biodegradable Chelating Agents," Environmental Science and Technology, Vol. 38, No. 3, 2004, pp. 937-944. doi:10.1021/es0348750

[5] C. S. H. Leung, C. F. Meares and D. A. Goodwin, "The Attachment of Metal-Chelating Groups to Proteins: Tagging of Albumin by Diazonium Coupling and Use of the Products as Radiopharmaceuticals," The International Journal of Applied Radiation and Isotopes, Vol. 29, No. 11,1978 , pp. 687-692. doi:10.1016/0020-708X(78)90107-2

[6] C. S.-H. Leung and C. F. Meares, "Attachment of Fluorescent Metal Chelates to Macromolecules Using 'Bifunctional' Chelating Agents," Biochemical and Biophysical Research Communications, Vol. 75, No. 1, 1977, pp. 149-155. doi:10.1016/0006-291X(77)91302-X

[7] C. J. Anderson, P. A. Rocque, C. J. Weinheimer and M. J. 
Welch, "Evaluation of Copper-Labeled Bifunctional Chelate-Albumin Conjugates for Blood Pool Imaging," Nuclear Medicine and Biology, Vol. 20, No. 4, 1993, pp. 461-467. doi:10.1016/0969-8051(93)90077-8

[8] E. M. Egorova and A. A. Revina, "Synthesis of Metallic Nanoparticles in Reverse Micelles in the Presence of Quercetin," Colloids and Surfaces A: Physicochemical and Engineering Aspects, Vol. 168, No. 1, 2000, pp. 87-96. doi:10.1016/S0927-7757(99)00513-0

[9] M. A. H. Muhammed, P. K. Verma, S. K. Pal, A. Retnakumari, M. Koyakutty, S. Nair and T. Pradeep, "Luminescent Quantum Clusters of Gold in Bulk by Albumin-Induced Core Etching of Nanoparticles: Metal Ion Sensing, Metal-Enhanced Luminescence, and Biolabeling," Chemistry-A European Journal, Vol. 16, No. 33, 2010, pp. 10103-10112. doi:10.1002/chem.201000841

[10] M. G. Guzmán, J. Dille and S. Godet, "Synthesis of Silver Nanoparticles by chemical Reduction Method and their antibacterial activity," World Academy of Science, Engineering and Technology, Vol. 43, 2008, pp. 357-364.

[11] S. D. Salomon, M. Bahadory, A. V. Jeyarajasingam, S. A.
Rutkowsky, C. Boritz and L. Mulfinger, "Synthesis and Study of Silver Nanoparticles," Journal of Chemical Education, Vol. 84, No. 2, 2007, pp. 322-325. doi:10.1021/ed084p322

[12] T. Maiyalagan, "Synthesis, Characterization and Electrocatalytic Activity of Silver Nanorods towards the Reduction of Benzyl Chloride," Applied Catalysis A: General, Vol. 340, No. 2, 2008, pp. 191-195. doi:10.1016/j.apcata.2008.02.016

[13] G. A. Martínez-Castañón, N. Niño-Martínez, F. MartínezGutierrez, J. R. Martínez-Mendoza and F. Ruiz, "Characterization of Silver Nanoparticles Synthesized on Titanium Dioxide Fine Particles," Nanotechnology, Vol. 19, No. 6, 2008, pp. 1343-1348.

[14] S. Panigrahi, S. Kundu, S. K. Ghosh, S. Nath and T. Pal, "General Method of Synthesis for Metal Nanoparticles," Journal of Nanoparticle Research, Vol. 6, 2004, pp. 411414.

[15] T. Tuval and A. Gedanken, "A Microwave-Assisted Polyol Method for the Deposition of Silver Nanoparticles on Silica Spheres," Nanotechnology, Vol. 18, 2007, p. 7. 